\title{
Fecal carriage of extended-spectrum $\beta$-lactamases and AmpC-producing Escherichia coli in a Libyan community
}

\author{
Salwa Fouad Ahmed ${ }^{1 *}$, Mostafa Mohamed M Ali ${ }^{2}$, Zienat Kamel Mohamed ${ }^{3}$, Tarek A Moussa ${ }^{3}$ and John D Klena ${ }^{1}$
}

\begin{abstract}
Background: Extended-spectrum $\beta$-lactamases (ESBLs), including the AmpC type, are important mechanisms of resistance among Enterobacteriaeceae. CTX-M type extended-spectrum $\beta$-lactamases, of which there are now over 90 variants, are distributed globally, yet appear to vary in regional distribution. AmpC $\beta$-lactamases hydrolyze third generation cephalosporins, but are resistant to inhibition by clavulanate or other $\beta$-lactamase inhibitors in vitro. Fecal carriage and rates of colonization by bacteria harboring these resistance mechanisms have been reported in patients with community-acquired infections and in healthy members of their households. Expression of these ESBLs compromises the efficacy of current antibacterial therapies, potentially increasing the seriousness of hospital-and community-acquired Escherichia coli (E. coli) infections.

To investigate the occurrence of ESBL-producing E. coli in human fecal flora isolated from two pediatric populations residing in the Libyan cities Zleiten and Abou El Khoms. Isolates were further studied to characterize genes encoding $\beta$-lactam resistance, and establish genetic relationships.

Methods: Antibiotic resistance profiles of phenotypically characterized E. coli isolates recovered from the stools of 243 Libyan children during two surveillance periods in 2001 and 2007 were determined by the disk diffusion method. ESBL-screening was performed using the cephalosporin/clavulanate double synergy disc method, and the AmpC-phenotype was confirmed by the aminophenyl-boronic acid test. ESBL genes were molecularly characterized. Phylogenetic group and multilocus sequence typing (MLST) were determined for ESBL-producing isolates and PFGE was performed to compare banding profiles of some dominant strains.

Results: ESBLs were identified in 13.4\% (18/134) of E. coli isolates, and nine isolates (6.7\%) demonstrated AmpC activity; all 18 isolates contained a CTX-M gene. Three CTX-M gene families (CTX-M-1, $n=9 ;$ CTX-M-15, $n=8$ and CTX-M-3, $n=1$ ) were distributed in diverse E. coli backgrounds (phylogenetic group D, 39\%; B2, 28\%; B1, 22\% and A, 11\%). MLST analysis revealed 14 sequence type (ST) with six new sequence types. The gene encoding the CMY-2 enzyme was detected in five AmpC-positive E. coli.
\end{abstract}

Conclusions: These results identified heterogeneous clones of CTX-M-producing E. coli in the fecal isolates, indicating that the intestinal tract acts as a reservoir for ESBL-producing organisms, and a trafficker of antibiotic resistance genes.

Keywords: ESBLs, Libya, CTXM, AmpC, Fecal carriage, E. coli, MLST

\footnotetext{
* Correspondence: salwa.fouad.eg@med.navy.mil

'United States Naval Medícal Research Unit No.3, Cairo, Egypt

Full list of author information is available at the end of the article
} 


\section{Background}

The emergence of extended-spectrum- $\beta$-lactamase (ESBL)producing E. coli in the community has been one of the most significant epidemiologic changes in infectious disease in recent years. The epidemiology of ESBL-associated infections is complex and combines the expansion of mobile genetic elements with specific clonal dissemination $[1,2]$. In the last decades, worldwide, Enterobacteriaceae producing ESBLs of the CTX-M type have shown a rapid and alarming dissemination and have been recognized as the most prevalent causative agents of hospital- and community-acquired infections [3-5]. The CTX-M- $\beta$ lactamases, of which there are now over 150 different types detected in very distant regions such as Europe, the Near and Far East, South America, North America, and more recently in Africa are responsible for the recent huge increment in ESBLs throughout the world [3,6-10]. With the wide distribution of these enzymes worldwide, it seems that there are predominant enzymes in each region (3). However, there is limited data regarding the molecular epidemiology of ESBL-producing Enterobacteriaceae in the Middle East and North Africa (MENA) [11,12].

Several studies have demonstrated the high prevalence and diverse clones of CTX-M-producing E.coli from healthy humans $[13,14]$ and have reported the rate of intestinal colonization by commensal $E$. coli isolates harboring ESBLs in healthy volunteers [15-18]. Despite the serious threat encountered by the transmission of these potentially harmful organisms in the community among healthy members of the same family unit, the rate of fecal carriage of ESBL-producing Enterobacteriaceae has mainly been investigated as part of nosocomial outbreak investigations [19] and the number of prospective longitudinal studies conducted in the hospital or in community settings remains rare [20]. In Libya, there is no a single report on the spread of bacterial resistance due to ESBL-producing isolates from either the hospital or community setting. We conducted the present study to investigate the occurrence of ESBL-positive $E$. coli isolates in human fecal flora and to characterize their encoding genes, and the clonal relationships.

\section{Methods}

\section{Bacterial isolates}

The research study was approved by U.S. Naval Medical Research Unit No. 3 in compliance with applicable Federal regulations governing the protection of human subjects. Informed consents were obtained from parents or legal guardians of minors. Stool samples were collected from 243 diarrheal libyan children aged from 3-12 years old at Al-Shafa Private Clinic and outpatient clinics of two Central Hospitals in Zliten and Alkhomes cities between April 2000 and March 2001 and the summer of 2007. A clinical history for each patient was obtained by an attending medical doctor and clinical symptoms, including fever, vomiting, and dehydration were recorded in a standard form. Within two hours of collection, stool specimens were directly streaked onto Mac-Conkey agar (Difco, Detroit, MI, USA) for isolation of $E$. coli. After overnight incubation at $37^{\circ} \mathrm{C}, 3$ lactose-fermenting colonies were selected from each case and identified by the API 20E System (Biomerieux, SA, Marcy, l'Etoile, France).

\section{Antibiotic susceptibility and ESBL detection}

Bacterial susceptibility to antibiotics was determined using the Kirby-Bauer agar disc diffusion method with bacterial isolates cultured on Mueller-Hinton agar. Susceptibility to ampicillin $(10 \mu \mathrm{g})$, cephalothin $(30 \mu \mathrm{g})$, chloramphenicol $(30 \mu \mathrm{g})$, nalidixic acid $(10 \mu \mathrm{g})$, streptomycin $(10 \mu \mathrm{g})$, tetracycline $(30 \mu \mathrm{g})$ trimethoprimsulphamethoxazole $(25 \mu \mathrm{g})$ ciprofloxacin $(5 \mu \mathrm{g})$, ceftriaxone $(30 \mu \mathrm{g})$, amoxicillin/clavulanate $(30 \mu \mathrm{g})$ cefotaxime $(30 \mu \mathrm{g})$, cefotaxime/clavulanate $(30 \mu \mathrm{g} / 10 \mu \mathrm{g})$, ceftazidime $(30 \mu \mathrm{g})$, ceftazidime/clavulanate $(30 / 10 \mu \mathrm{g})$, ampicillin sulbactam $(20 \mu \mathrm{g})$ and imipenem $(10 \mu \mathrm{g})$ was determined; all antibiotics were purchased from Oxoid (Milan, Italy). Results were interpreted using published criteria from the Clinical Laboratory Standards Institute (CLSI) [21]. For reporting, intermediate and susceptible isolates are referred to as "non-resistant. Multi-drug resistance was defined as resistance to at least three families of antibiotics. ESBL activity was screened using the double-synergy test [22]. E. coli ATCC 25922 and Pseudomonas aeruginosa ATCC 27853 were used as control strains for susceptibility studies as recommended by CLSI 2011 guidelines for Enterobacteriaceae [21]. Phenotypic detection of AmpC production was performed using an amino-phenyl-boronic acid (APB)-based test as previously described [23].

\section{ESBL and AmpC characterization}

Total bacterial DNA was purified using QIAmp DNA mini kits (Qiagen, Valencia, CA, USA) according to the manufacturer's instructions. Genes encoding $\beta$-lactamase enzymes were amplified using previously described primers $[24,25]$. PCR products were purified using QIAquick PCR purification kits (Qiagen) following the manufacturer's instructions. Sequencing reactions were carried out using the Perkin Elmer Big Dye kit v3.1 (Applied Biosystems, Foster City, CA, USA). Sequence data were collected using an ABI Prism 3100 automated sequencer, coupled to data collection software version 2.0, and sequencing analysis software 5.1.1 (Applied Biosystems). Nucleotide sequences obtained were assembled using BioEdit (version 7.0.5.3) and aligned with GenBank reference sequences using the Clustal X application within BioEdit. 


\section{Molecular typing and phylogenetic groups of ESBL-positive isolates}

The phylogenetic grouping of ESBL-positive $E$. coli isolates was determined using a previously described PCR-based method [26]. MLST was performed on all 18 CTX-Mproducing ESBL isolates using the $E$. coli MLST scheme described at http://mlst.ucc.ie/mlst/dbs/E.coli, based on sequencing of internal regions of the housekeeping genes adk, fumC, gyrB, icd, $m d h$, purA, and recA [27]. CTX-M-1-producing $E$. coli isolates with a dominant MLST sequence type were further characterized using pulsed-field gel electrophoresis (PFGE) following a standardized protocol established by PulseNet USA, U.S. Centers for Disease Control and Prevention, for E. coli O157:H7 (PulseNet, USA) [28].

\section{Data analyses}

Nucleotide sequences obtained from various isolates were aligned with GenBank reference sequences using the Clustal X application within BioEdit software (version 7.0.5.3), and compared with published sequences in the Lahey organization (http://www.lahey.org/studies). Data were statistically described in terms of frequencies (number of cases) and relative frequencies (percentages). Fisher's exact test was used for comparison, a probability value ( $\mathrm{P}$ value) less than 0.05 was considered statistically significant. All statistical calculations were done using Microsoft Excel 2007 (Microsoft Corporation, New York, USA), SPSS (Statistical Package for the Social Science; SPSS Inc., Chicago, IL, USA) or Quick Calcs Online calculators for scientists (Graph pad software Inc., San Diego, CA, USA).

\section{Results}

Detection of ESBL-producing isolates

One hundred and thirty-four confirmed $E$. coli isolates were recovered from the stools of 243 Libyan children during the two study periods (Table 1). Sixteen isolates from 2001 and five isolates from 2007 of the total 134 E. coli were from diarrheagenic cases (previously tested positive for virulence characteristics (29); the remaining 113 isolates were from non- diarrheagenic E. coli (negative for virulence factors [29]). Resistance to third generation cephalosporins (e.g., cefotaxime, ceftriaxone and ceftazidime) was observed in $20 \%$ of isolates, more often observed in the first surveillance period (2000-2001). Of the 14 antimicrobial agents tested, E. coli isolated from Libyan children in 2001 were significantly more resistant to cephalothin, cefotaxime, ceftriaxone, ceftazidime, chloramphenicol, nalidixic acid and Ciprofloxacin than total E. coli from Libyan children in 2007 (Table 1). Overall, the percentage of ESBL positive isolates was $13.4 \%(18 / 134)$ with no significant occurrence $(\mathrm{P}=0.2)$ in $2001(14 / 85)$ as compared to $2007(4 / 49)$ (Table 2). The AmpC phenotype was detected in $6.7 \%(9 / 134)$ of $E$. coli and was mainly associated with $E$. coli isolates from 2001 isolates (Table 2). In addition to the $27.8 \%(5 / 18)$ resistance to both NA and CIP, ESBL-positive isolates displayed a significant higher level of multi-drug resistance to 12 of 14

Table 1 Antibiotic resistance of Esherichia coli strains isolated from Libyan children during $2001 \& 2007$

\begin{tabular}{|c|c|c|c|c|}
\hline Antibiotic & $\begin{array}{c}2001 \\
(\mathrm{~N}=85)\end{array}$ & $\begin{array}{c}2007 \\
(N=49)\end{array}$ & P-values* & $\begin{array}{c}\text { Total } \\
(\mathrm{N}=134)\end{array}$ \\
\hline Ampicillin & $69(81.2)^{* *}$ & $36(73.5)$ & 0.3 & $105(78.4)$ \\
\hline Ampicillin/Sulbactam & $50(58.8)$ & $26(53.1)$ & 0.5 & $76(56.7)$ \\
\hline Amoxicillin/Clavulanic & $54(63.5)$ & $32(65.3)$ & 0.8 & $86(64.2)$ \\
\hline Imipenem & 0 & 0 & N/A & $0(0.0)$ \\
\hline Cephalothin & $67(78.8)$ & $30(61.2)$ & 0.03 & $97(72.4)$ \\
\hline Cefotaxime & $23(27.1)$ & $4(8.2)$ & 0.009 & $27(20.2)$ \\
\hline Ceftriaxone & $22(25.9)$ & $4(8.2)$ & 0.01 & $26(19.4)$ \\
\hline Ceftazidime & $23(27.1)$ & $4(8.2)$ & 0.009 & $27(20.2)$ \\
\hline Chloramphenicol & 39 (45.9) & $8(16.3)$ & 0.0005 & $47(35.1)$ \\
\hline Nalidixic acid & $4(4.7)$ & $9(18.4)$ & 0.01 & $13(9.7)$ \\
\hline Ciprofloxacin & $2(2.4)$ & $5(62.5)$ & $<0.0001$ & $7(5.2)$ \\
\hline Streptomycin & $57(67.1)$ & $28(57.1)$ & 0.2 & $85(63.4)$ \\
\hline Trimethoprim/sulfamethoxazole & $54(63.5)$ & $29(59.2)$ & 0.6 & $83(61.9)$ \\
\hline Tetracycline & $48(56.5)$ & $22(44.9)$ & 0.2 & $70(52.2)$ \\
\hline
\end{tabular}

* Fisher's exact test.

**Data presented as $\mathrm{N}(\%)$ of resistance cases, where $\mathrm{N}$ : Number of cases displaying resistance.

N/A: Not applicable. 
Table 2 Extended-spectrum beta-lactamase and AmpC phenotypes of Esherichia coli strains in human fecal samples from Libyan children

\begin{tabular}{lcccc}
\hline $\begin{array}{l}\text { Beta-lactamase } \\
\text { phenotype }\end{array}$ & $\begin{array}{c}\mathbf{2 0 0 1} \\
\mathbf{( N = 8 5 )}\end{array}$ & $\begin{array}{c}\mathbf{2 0 0 7} \\
\mathbf{( N = 4 9 )}\end{array}$ & $\begin{array}{c}\mathbf{P}- \\
\text { Values* }\end{array}$ & $\begin{array}{c}\text { Total } \\
\mathbf{( N = 1 3 4 )}\end{array}$ \\
\hline ESBL & $14(16.5)^{* *}$ & $4(8.2)$ & 0.3 & $18(13.4)$ \\
AmpC & $9(10.6)$ & $0(0)$ & 0.07 & $9(6.7)$ \\
\hline
\end{tabular}

* Fisher's exact test.

**Data presented as $\mathrm{N}(\%)$ of resistance cases, where $\mathrm{N}$ : Number of cases displaying resistance.

antimicrobial agents tested as compared to ESBL-negative isolates (Table 3).

\section{Characterization of blaESBL and blaAMPC in ESBL-producing isolates}

PCR amplification and DNA sequence analyses of the 18 ESBL-producers showed that all possessed a CTX-M-type ESBL and revealed three families of blaCTX-M; blaCTXM-1 ( $\mathrm{n}=9)$, blaCTX-M-15 $(\mathrm{n}=8)$, and blaCTX-M-3 $(n=1)$. All of the CTX-M positive isolates were also positive for blaTEM, while $16.7 \%$ of isolates carried either blaSHV-2 or blaOXA-1 (Table 4). None of the CTX-M-1 family members demonstrated resistance to ciprofloxacin; however, a relationship with fluoroquinolone resistance was noted with ESBL-producing isolates harboring the blaCTX-M-15. The gene encoding the CMY-2 enzyme was detected in five AmpC-positive E. coli.

\section{Molecular typing of ESBL-positive isolates}

The genetic background of the 18 ESBL positive isolates revealed their distribution into four phylogenetic groups (Table 4): 39\% (7/18) were group D, 28\% (5/18) were group $\mathrm{B} 2$, and $22 \%(4 / 18)$ were group B1 while two isolates (11\%) belonged to group A. Five of the nine blaCTX-M-1 isolates belonged to phylogroup $\mathrm{D}$ and the remaining four belonged to phylogroup B2. Because CTX-M-1 predominated during the first surveillance period, we were eager to study their genetic backgrounds. PFGE analysis on blaCTX-M-1 isolates identified three major band patterns (see Additional file 1): pattern 1 consisted of three isolates with indistinguishable macrorestiction profile (mrp), pattern 2 consisted of one isolate with an unique mrp, and pattern 3 included three isolates: 2 isolates with indistinguishable mrp, and one isolate had a single band difference from pattern 3 and was named $3 \mathrm{a}$. The unique CTX-M-15 producing isolates demonstrated a distinct pattern 4 from that displayed by CTX-M-1. MLST analyses revealed that the blaCTX-M-1 isolates with pattern 1 belonged to a new ST group, while those with profile 2, 3 and 3a belonged to ST12. MLST revealed an additional eight ST groups in which the remaining nine ESBL-producing isolates [CTX-M-15, (ST127, ST359 $(\mathrm{n}=2)$, ST NEW, ST155, ST38, ST 46, ST410); CTX-M-3, (ST23)] were grouped (Table 4).

\section{Discussion}

In this study we investigated the occurrence of ESBLs in human fecal flora from Libyan children living in two

Table 3 Antibiotic resistance of Esherichia coli according to extended-spectrum beta-lactamases phenotype in fecal samples from Libyan children

\begin{tabular}{|c|c|c|c|c|}
\hline & $\begin{array}{c}\text { ESBL + ve } \\
(\mathrm{N}=18)\end{array}$ & $\begin{array}{l}\text { ESBL-ve } \\
(\mathrm{N}=116)\end{array}$ & P-Value* & $\begin{array}{c}\text { Total } \\
(\mathrm{N}=\text { I34) }\end{array}$ \\
\hline Ampicillin & $18(100)^{* *}$ & $87(75)$ & 0.02 & $105(78.4)$ \\
\hline Ampicillin/Sulbactam & $17(94.4)$ & $59(50.9)$ & 0.0005 & $76(56.7)$ \\
\hline Amoxicillin/Clavulanic & $17(94.4)$ & $69(59.5)$ & 0.3 & $86(64.2)$ \\
\hline Imipenem & $0(0.0)$ & $0(0.0)$ & N/A & $0(0.0)$ \\
\hline Cephalothin & $18(100)$ & $79(68.1)$ & $0.003 /$ & $97(72.4)$ \\
\hline Cefotaxime & $18(100)$ & $9(7.8)$ & $<0.0001$ & $.27(20.2)$ \\
\hline Ceftriaxone & $18(100)$ & $8(6.9)$ & $<0.0001$ & $26(19.4)$ \\
\hline Ceftazidime & $18(100)$ & $9(7.8)$ & $<0.0001$ & $27(20.2)$ \\
\hline Chloramphenicol & $17(94.4)$ & $30(25.9)$ & $<0.0001$ & $47(35.1)$ \\
\hline Nalidixic acid & $5(27.8)$ & $8(6.9)$ & 0.03 & $13(9.7)$ \\
\hline Ciprofloxacin & $5(27.8)$ & $2(1.7)$ & 0.0009 & $7(5.2)$ \\
\hline Streptomycin & $16(88.9)$ & $69(59.5)$ & 0.02 & $85(63.4)$ \\
\hline Trimethoprim/sulfamethoxazole & $14(77.8)$ & $69(59.5)$ & 0.2 & $.83(61.9)$ \\
\hline Tetracycline & $16(88.9)$ & $54(46.6)$ & 0.001 & $70(52.2)$ \\
\hline
\end{tabular}

*Fisher's exact test.

**Data presented as $\mathrm{N}(\%)$, where $\mathrm{N}$ : Number of cases displaying resistance.

N/A: Not applicable. 


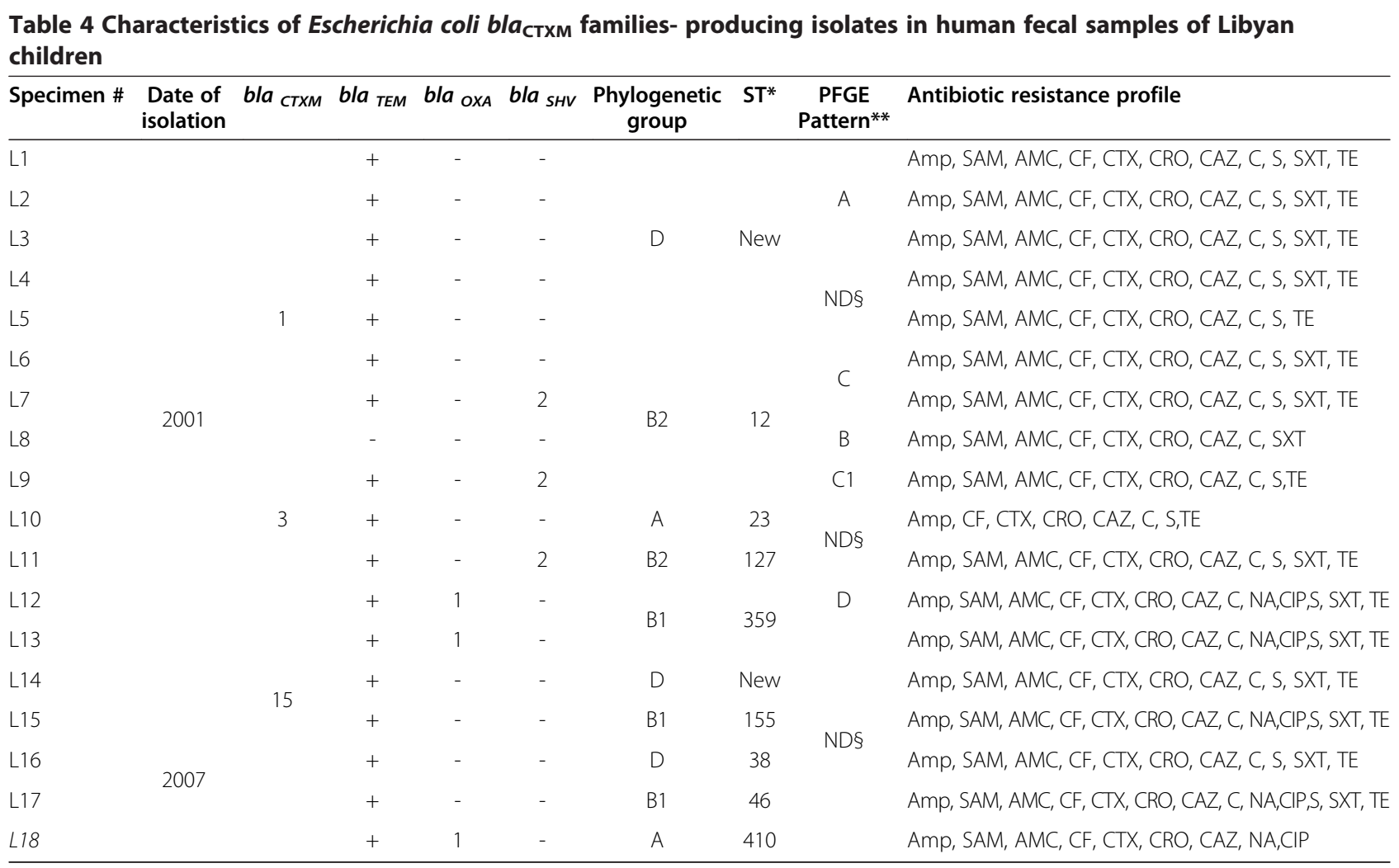

*ST: Sequence type as analyzed by multi-locus sequence typing (MLST). **PFGE : Pulse-Field gel electrophoresis. §ND: Not done.

Amp, ampicillin; SAM, sulbactam-ampicillin; AMC, amikacin; CF, cephalothin; CTX, cefotaxime; CRO, ceftraxione; CAZ, ceftazidime; C, chloramphenicol; NA, nalidixic acid; CIP, ciprofloxacin; S, streptomycin; SXT, sulfamethoxazole/trimethoprim; TE, tetracycline.

cities during two time periods. Overall, the percentage of fecal ESBL-producing E. coli recovered is comparable to those reported from other parts of the world including Saudi Arabia [30] and Tunisia [14], but lower than those found in Egypt [18], Thailand [17], China [13], and Japan [31]. In our study, the majority of ESBL-producing $E$. coli was isolated from patients with community-acquired infections and not from hospitalized patients with diarrhea which suggests the ability of ESBL-producing isolates to spread in the community beyond the hospital environment and potentially exclude their limitation to nosocomial infections, thus helping to exacerbate public health concerns [5]. Leflont et al. [32] have recently reported the increased rate of ESBL fecal carriage in healthy subject populations living in Paris from a $0.6 \%$ to $6 \%$ over a five year period and indicated that acquisition from a common source related to food and person-toperson transmission may contribute to the spread of ESBL-producing $E$. coli within families.

The presence of these organisms in the bowel in high rates was suggested to be a risk factor for infections with these bacteria and their dissemination in fecal flora [33]. In developing countries most patients received antimicrobial treatment without prescription, such common practices in nearly all developing countries exert a selective pressure on $E$. coli organisms, known to be a common cause of community-acquired infections, [34] to develop such resistance that leads to a potential sustainable source for nosocomial infections. In our study, blaCTX-M gene was detected in all 18 ESBL-producing E. coli isolates and blaCTX-M-1 was the most commonly identified resistance mechanism in samples from the earliest surveillance point (April 2000 to March 2001). Of particular interest in this region, the existence of three types of CTX-M families identified during the first year of study with a preponderance of CTX-M-1 in previous year and a persistence of CTX-M-15 later.

This finding supports work by others indicating that a specific CTX-M enzyme can dominate in a geographical region [3]. A possible explanation could be due to the dynamic nature of organisms harboring these enzymes; over time the dominant mechanism will change, as the dominant clonal group changes. While CTX-M-15 is the most common CTX-M type in the Middle East region and North Africa, other investigators have reported that CTX-M-15 was not more prevalent than CTX-M-1 among the fecal isolates [16,35]. The difference in distribution of CTX-M types was also attributed by some 
studies to the various sources of the CTX-M-producing $E$. coli isolates carried in the gut of patients [15]. Some previous reports suggested a possible transmission of ESBL-producing E. coli through the food chain [36]; interestingly, it was shown, particularly in France, that CTX-M-1 is the predominant CTX-M among food-producing animals [37].

In general, CTX-M-producing E. coli have predominantly been identified from the community as a cause of urinary tract infections. However, the high rate of their fecal shedding in the outpatient setting in Libya is an emerging epidemiological problem that requires application of updated control measures like routine rectal screening of patients admitted from the community, even though routine fecal examination sounds impractical and is not required even if the patients were admitted to an intensive care unit in most hospitals and institutions around the world [38].

It is worth-mentioning that CTX-M $\beta$-lactamase genes are widely known to be carried on a plasmid linked to mobile genetic elements that are utilized as vehicles for resistance genes horizontal movement, in addition to carry on resistance to other drug like aminoglycoside and fluoroquinolone $[15,39,40]$. CTX-M isolates from the current study demonstrated resistance to non- $\beta$-lactam classes including the aminoglycoside and fluoroquinolone families.

The coexistence of AmpC phenotype in an ESBL isolate is a serious phenomenon that can mask the accurate detection of the ESBL phenotype [41]; this might have a critical effect on the success of clinical treatment. In our study, nine CTX-M positive isolates exhibited AmpC phenotype and CMY-2 was the main gene detected. Other AmpC genes previously reported (23) were not tested for the remaining negative samples. A recent study from Egypt has reported the occurrence of both resistance mechanisms for ESBL Enterobacteriaceae from outpatients and hospitalized cases, recommending the proper use of modified double-disc synergy test (MDDST), in addition to confirmatory PCR testing in order to avoid the unsuccessful identification of such isolates when they coexist [23].

Multiple studies have associated the dissemination of ESBL-CTX-M-15-producing isolates with the spread of the epidemic ST131 E. coli strain belonging to phylogenic group B2 [12,33]. Interestingly, our phylogenetic group analysis demonstrated that most of CTX-M-15 positive isolates did not fall under B2 group, and according to the MLST typing system, epidemic ST131 clone, most globally ST associated with CTX-M-15, was not identified, indicating that this clone is less represented in fecal ESBL-producing E. coli, which is in agreement with other recent studies from Tunisia [15] and Spain [36]. In contrast, the present study identified seven ST clones associated with the dissemination of CTX-M-15 that are not previously implicated in isolates producing-ESBL, in addition to two emerged ST reported earlier in Spain (ST155) and Tunisia (ST23) from fecal E. coli with carbapenamases and ESBL activites, respectively. This particular characteristic of Libyan CTX-M-15 isolates indicates that their dissemination occurred by heterogeneous clones with a different genetic background.

In summary, this is the first detailed description of fecal CTX-M-producing E. coli in Libya. The dynamic nature and high clonal diversity of fecal CTX-Mproducing isolates amplify the importance of the intestinal tract to act as a reservoir for ESBL-producing organisms, and a trafficker of antibiotic resistance genes. The increased prevalence of these organisms in human fecal flora and their establishment in the community represent an opportunity for these clones to become persistent. Because of the significant public health implications, the spread of organisms producing CTX-Mproducing isolates merits close monitoring with enhanced surveillance efforts [31], with the introduction of molecular diagnostic procedures in a clinical or reference laboratory to track their spread in the community and hospital settings.

\section{Limitation}

Although the number of isolates studied is too low to obtain a clear conclusion, coupled with the lack of identifiable risk factors, we cannot underscore the potential risk associated with the dissemination of these organisms in Libyan hospitals and the community at large. Therefore, a wider hospital and population-based surveillance study should be implemented over a distinct period of time to be able to truly reflect the molecular epidemiology of CTX-M-producing E. coli strains on a country-wide scale. In addition, the true reservoir of CTX-M-producers E. coli in normal healthy individuals should be investigated.

\section{Additional file}

Additional file 1: Mrp: Macro-restriction pattern as determined by PFGE. ST: Sequence type as analyzed by MLST. E.coli gp: E.coli

Phylogenetic group. Lane1-4: CTX-M-producing E.coli isolates (L1, L8, L5 \& L2); lane5-8 (L6, L7, L9 \& L12); lane 9: S.branderup.

\section{Competing interests}

The authors declare that they have no competing interests.

\section{Authors' contributions}

SFA and JDK designed and supervised molecular genetic studies, and wrote the manuscript. MMA carried out the molecular genetic studies and participated in data analysis. ZKM and TAM reviewed the manuscript and data content. All authors read and approved the final manuscript. 


\section{Acknowledgments}

The technical support of Mr. Salem Ibrahim Abdel-Hakam is highly acknowledged. Special Thanks to Mrs. Manal Mostafa for her assistance in the statistical analysis.

\section{Copyright assignment statement}

SFA and JDK are employees of the U.S. Government. This work was prepared as part of their official duties. Title 17 U.S.C. \$105 provides that 'Copyright protection under this title is not available for any work of the United States Government.' Title 17 U.S.C. §101 defines a U.S. Government work as a work prepared by a military service member or employee of the U.S. Government as part of that person's official duties.

\section{Author details}

${ }^{1}$ United States Naval Medícal Research Unit No.3, Cairo, Egypt. ²Department of Microbiology and Immunology, Faculty of Medicine, University of Tripolí, Tripoli, Libya. ${ }^{3}$ Department of Botany, Faculty of Science, Cairo University, Cairo, Egypt.

Received: 18 January 2014 Accepted: 30 April 2014

Published: 16 June 2014

\section{References}

1. Coque TM, Novais A, Carattoli A, Poirel L, Pitout J, Peixe L, Baquero F, Cantón R, Nordmann P: Dissemination of clonally related Escherichia coli strains expressing extended-spectrum $\beta$-lactamase CTX-M-15. Emerg Infect Dis 2008, 14:195-200.

2. Novais A, Cantón R, Valverde A, Machado E, Galán JC, Peixe L, Carattoli A, Baquero F, Coque TM: Dissemination and persistence of blaCTX-M-9 are linked to class 1 integrons containing CR1 associated with defective transposon derivatives from Tn402 located in early antibiotic resistance plasmids of IncHI2, IncP1-a, and IncFI groups. Antimicrob Agents Chemother 2006, 50:2741-2750.

3. Bonnet R: Growing group of extended-spectrum b-lactamases: the CTX-M enzymes. Antimicrob Agents Chemother 2004, 48:1-14

4. Canton R, Coque TM: The CTX-M $\beta$-lactamase pandemic. Curr Opin Microbiol 2006, 9:466-475.

5. Pitout JD, Nordmann P, Laupland KB, Poirel L: Emergence of Enterobacteriaceae producing extended-spectrum $\beta$-lactamases (ESBLs) in the community. J Antimicrob Chemother 2005, 56:52-59.

6. Elaldi N1, Gozel MG, Kolayli F, Engin A, Celik C, Bakici MZ, Vahaboglu H: Community-acquired CTX-M-15-type ESBL-producing Escherichia coli meningitis: a case report and literature review. J Infect Dev Ctries 2013, 13:424-431.

7. Moland ES, Black JA, Hossain A, Hanson ND, Thomson KS, Pottumarthy S: Discovery of CTX-M-like extended-spectrum beta-lactamases in Escherichia coli isolates from five U.S. states. Antimicrob Agents Chemother 2003, 47:2382-2383.

8. Woerther PL, Burdet C, Chachaty E, Andremont A: Trends in human fecal carriage of extended- spectrum $\beta$-lactamases in the community:toward the globalization of CTX-M. Clin Microbiol Rev 2013, 26:744-758.

9. Luvsansharav U-O, Hirai I, Nakata A, Imura K, Yamauchi K, Niki M, Komalamisra C, Kusolsuk T, Yamamoto Y: Prevalence of and risk factors associated with faecal carriage of CTX-M $\beta$-lactamase-producing Enterobacteriaceae in rural Thai communities. J Antimicrob Chemother 2012, 67:1769-1774.

10. Birgy A, Cohen R, Levy C, Bidet $P$, Courroux C, Benani M, Thollot F, Bingen E: Community faecal carriage of extended-spectrum beta-lactamase-producing Enterobacteriaceae in french children. BMC Infect Dis 2012, 12:1-5.

11. Dahmen S, Bettaieb D, Mansour W, Boujaafar N, Bouallegue O, Arlet G: Characterization and molecular epidemiology of extended-spectrum $\beta$-lactamases in clinical isolates of Enterobacteriaceae in a Tunisian University hospital. Microb Drug Resist 2010, 16:163-170.

12. Moubareck C, Daoud Z, Hakime NI, Hamze M, Mangeney N, Matta H, Mokhbat JE, Rohban R, Sarkis DK, Doucet-Populaire D: Countrywide spread of community- and hospital-acquired extended-spectrum -lactamase (CTX-M-15)-producing Enterobacteriaceae in Lebanon. J Clin Microbiol 2005, 43:3309-3313.

13. Li B, Sun JY, Liu QZ, Han LZ, Huang XH, Ni YX: High prevalence of CTX-M $\beta$-lactamases in faecal Escherichia coli strains from healthy humans in Fuzhou, China. Scand J Infect Dis 2011, 43:170-174.
14. Pallecchi L, Bartoloni A, Fiorelli C, Mantella A, Di Maggio T, Gamboa H, Gotuzzo E, Kronvall G, Paradisi F, Rossolini GM: Rapid dissemination and diversity of CTX-M extended-spectrum $\beta$-lactamase genes in commensal Escherichia coli isolates from healthy children from low-resource settings in Latin America. Antimicrob Agents Chemother 2007, 51:2720-2725.

15. Ben Sallem R, Ben Slama K, Estepa $V$, Jouini A, Gharsa H, Klibi N, Sáenz Y, Ruiz-Larrea F, Boudabous A, Torres C: Prevalence and characterisation of extended-spectrum $\beta$-lactamase (ESBL)-producing Escherichia coli isolates in healthy volunteers in Tunisia. Eur J Clin Microbiol Infect Dis 2012, 31:1511-1516.

16. Luvsansharav UO, Hirai I, Niki M, Sasaki T, Makimoto K, Komalamisra C, Maipanich W, Kusolsuk T, Sa-Nguankiat S, Pubampen S, Yamamoto Y: Analysis of risk factors for a high prevalence of extended-spectrum $\beta$-lactamase-producing Enterobacteriaceae in asymptomatic individuals in rural Thailand. J Med Microbiol 2011, 60:619-624.

17. Abdul Rahman EM, El-Sherif $\mathrm{RH}$ : High rates of intestinal colonization with extended-spectrum lactamase-producing Enterobacteriaceae among healthy individuals. J Invest Med 2011, 59:1284-1286.

18. Hollander R, Ebke M, Barck H, von Pritzbuer E: Asymptomatic carriage of Klebsiella pneumoniae producing extended-spectrum $\beta$-lactamase by patients in a neurological early rehabilitation unit: management of an outbreak. J Hosp Infect 2001, 48:207-213.

19. Bonomo RA, Donskey CJ, Blumer JL, Hujer AM, Hoyenm CK, Jacobs MR, Whalen CC, Salata RA: Cefotaxime-resistant bacteria colonizing older people admitted to an acute care hospital. J Am Geriatr Soc 2003, 51:519-522.

20. Mirellis B, Navarro F, Miró E, Mesa RJ, Coll P, Prats G: Community transmission of extended spectrum Beta-lactamases. Emerg Infect Dis 2003, 9:1024-1025.

21. Clinical and Laboratory Standards Institute: Performance Standards for Antimicrobial Susceptibility Testing; Twenty First informational Supplement, CLSI document M 100-S21. Wayne, PA; USA: Clin and Lab standards Institute; 2011.

22. Jarlier $V$, Nicolas MH, Fournier G, Philippon A: Extended broad-spectrum b-lactamases conferring transferable resistance to newer $\beta$-lactam agents in Enterobacteriaceae: hospital prevalence and susceptibility patterns. Rev Infect Dis 1988, 10:867-878.

23. Fam N, Gamal D, El Said M, Abou-Fadl L, El Dabei E, El Attar S, Sorur A, Fouad S, Klena J: Detection of plasmid-Mediated AmpC Beta-Ictamass in clinically significant bacterial isolates in a research institute hospital in Egypt. Life Sci J 2013, 10:2294-2302.

24. Newire EA, Ahmed SF, House B, Valiente E, Pimentel G: Detection of new SHV-12, SHV-5 and SHV-2a variants of extended spectrum Beta-lactamase in Klebsiella pneumoniae in Egypt. Ann Clin Microbiol Antimicrob 2013, 12:1-12.

25. Chen S, Zhao S, White DG, Schroeder CM, Lu R, Yang H, McDermott PF, Ayers SJ, Meng J: Characterization of multiple-antimicrobial-resistant Salmonella serovars isolated from retail meats. Appl Environ Microbiol 2004, 70:1-7.

26. Clermont O, Bonacorsi S, Bingen E: Rapid and simple determination of the Escherichia coli phylogenetic group. Appl Environ Microbiol 2000, 66:4555-4558.

27. Wirth $T$, Falush D, Lan R, Colles F, Mensa P, Wieler LH, Karch H, Reeves PR, Maiden MC, Ochman H, Achtman M: Sex and virulence in Escherichia coli: an evolutionary perspective: Mol. Microbiol 2006, 60:1136-1151.

28. PulseNet USA: One-Day (24-28h): Standardized laboratory protocol for molecular subtyping of Escherichia coli 0157:H7, Salmonella serotypes, and Shigella sonnei by Pulsed Field Gel Electrophoresis (PFGE). Pulse Net Internat. 2009. http://www.pulsenetinternational.org/assets/PulseNet/ uploads/pfge/PNL05_Ec-Sal-ShigPFGEprotocol.pdf.

29. Ali MMM, Mohamed ZK, Klena JD, Ahmed SF, Moussa TAA, Ghenghesh KS: Molecular characterization of Diarrheagenic Escherichia coli from Libya. Am J Trop Med Hyg 2012, 86:866-871.

30. Kader AA, Kumar A, Kamath KA: Fecal carriage of extended-spectrum b-lactamase-producing Escherichia coli and Klebsiella pneumoniae in patients and asymptomatic healthy individuals. Infect Control Hosp Epidemiol 2007, 28:1114-1116.

31. Luvsansharav UO, Hirai I, Niki M, Nakata A, Yoshinaga A, Moriyama T, Yamamoto Y: Prevalence of fecal carriage of extended-spectrum $\beta$-lactamase-producing Enterobacteriaceae among healthy adult people in Japan. J Infect Chemother 2011, 17:722-725.

32. Leflon-Guibout V, Blanco J, Amaqdouf K, Mora A, Guize L, Nicolas-Chanoine $\mathrm{MH}$ : Absence of CTX-M enzymes but high prevalence of clones, including 
clone ST131, among fecal Escherichia coli isolates from healthy subjects living in the area of Paris, France. J Clin Microbiol 2008, 46:3900-3905.

33. Rossi F, Baquero F, Hsueh PR, Paterson DL, Bochicchio GV, Snyder TA, Satishchandran V, McCarroll K, DiNubile MJ, Chow JW: In vitro susceptibilities of aerobic and facultatively anaerobic Gram-negative bacilli isolated from patients with intra-abdominal infections worldwide: 2004 results from SMART (Study for Monitoring Antimicrobial Resistance Trends). J Antimicrob Chemother 2006, 58:205-210.

34. Nicolas-Chanoine MH, Coraline Gruson C, Bialek-Davene S, Bertrand X, Thomas-Jean F, Bert F, Moyat M, Meiller E, Marcon E, Danchin N, Noussair L, Moreau R, Leflon-Guibout V: 10-Fold increase (2006-11) in the rate of healthy subjects with extended-spectrum $\beta$-lactamase-producing Escherichia coli faecal carriage in a Parisian check-up centre. J Antimicrob Chemother 2013, 68:562-568.

35. Cortés P, Blanc V, Mora A, Dahbi G, Blanco JE, Blanco M, López C, Andreu A, Navarro F, Alonso MP, Bou G, Blanco J, Llagostera M: Isolation and characterization of potentially pathogenic antimicrobial-resistant Escherichia coli strains from chicken and pig farms in Spain. Appl Environ Microbiol 2010, 76:2799-2805.

36. Girlich D, Poirel L, Carattoli A, Kempf I, Lartigue MF, Bertini A, Nordmann P: Extended-spectrum $\beta$-lactamase CTX-M-1 in Escherichia coli isolates from healthy poultry in France. Appl Environ Microbiol 2007, 73:4681-4685.

37. Pitout JD, Laupland KB: Extended spectrum $\beta$-lactamases producing Enterobacteriaceae: an emerging public-health concern. Lancet Infect Dis 2007, 8:159-166

38. Morosini Ml, García-Castillo M, Coque TM, Valverde A, Novais A, Loza E, Baquero F, Cantón R: Antibiotic coresistance in extended-spectrum- $\beta$-lactamase-producing Enterobacteriaceae and in vitro activity of tigecycline. Antimicrob Agents Chemother 2006, 50:2695-2699.

39. Yu HS, Lee JC, Kang HY, Jeong YS, Lee EY, Choi CH, Tae SH, Lee YC, Seol SY, Cho DT: Prevalence of dfr genes associated with integrons and dissemination of dfrA17 among urinary isolates of Escherichia coli in Korea. J Antimicrob Chemother 2013, 53(3):445-450.

40. Fam NS, El-Damarawy MM: CTX-M15 extended-spectrum- $\beta$-lactamase detected from intensive care unit of an Egyptian medical research institute. Res J Med Sci 2008, 3:84-91.

41. Gijón D, Curiao T, Baquero F, Coque TM, Cantón R: Fecal carriage of carbapenemase-producing Enterobacteriaceae: a hidden reservoir in hospitalized and nonhospitalized patients. J Clin Microbiol 2012, 50(5):1558-1563.

doi:10.1186/1476-0711-13-22

Cite this article as: Ahmed et al:: Fecal carriage of extended-spectrum $\beta$-lactamases and AmpC-producing Escherichia coli in a Libyan community. Annals of Clinical Microbiology and Antimicrobials 2014 13:22.

\section{Submit your next manuscript to BioMed Central and take full advantage of:}

- Convenient online submission

- Thorough peer review

- No space constraints or color figure charges

- Immediate publication on acceptance

- Inclusion in PubMed, CAS, Scopus and Google Scholar

- Research which is freely available for redistribution

Submit your manuscript at www.biomedcentral.com/submit
Ciomed Central 